ББК 63.4

\author{
Организация конференциии и издание материалов проведень \\ при финансовой поддержке Российского фонда фундаментальных исследований, \\ проект № 19-09-20008
}

Утверждено к печати Ученым советом ИИМК РАН

Редакционная коллегия тома I: В. А. Алёкшин, Л. Б. Кирчо (отв. редакторы),

В. П. Никоноров, В. Я. Стёганцева; В. В. Терёхина

Рецензенты: д. и. н. Л. Б. Вишняцкий, д. и. н. А. А. Выборнов

Программный комитет конференции: академик РАН, д. и. н., проф. М. Б. Пиотровский

(Государственный Эрмитаж, почетный председатель); д. и. н. В. А. Лапшин (ИИМК РАН, председатель); д. и. н. А. В. Головнёв (МАЭ РАН, сопредседатель); д. и. н. В. А. Дергачёв (Высшая антропологическая школа, Молдова, сопредседатель); д. и. н. И. Ф. Попова (ИВР РАН, сопредседатель); академик АН Республики Узбекистан, д. и. н., проф. Э. В. Ртвеладзе (сопредседатель); к. и. н. А. В. Поляков (ИИМК РАН, зам. председателя); к. и. н. В. А. Алёкшин (ИИМК РАН, зам. председателя); д. и. н. Ю. Е. Берёзкин (МАЭ РАН); Dr., Prof. Н. Бороффка (Германский археологический институт, Германия); В. С. Бочкарёв (ИИМК РАН); Dr. Э. Кайзер (Свободный университет Берлина, Германия); к. и. н. М. Т. Кашуба (ИИМК РАН); д. и. н. Л. Б. Кирчо (ИИМК РАН); к. и. н. А. В. Кияшко (Южный федеральный университет); к. и. н. П. Ф. Кузнецов (СГСПУ);

к. и. н. Н. М. Малов (СНИГУ); к. и. н. В. П. Никоноров (ИИМК РАН); Ю. Ю. Пиотровский

(Государственный Эрмитаж); д. и. н., проф. Д. Г. Савинов (Институт истории СПбГУ);

к. и. н. В. Н. Седых (Институт истории СПбГУ); к. и. н. Н. Н. Скакун (ИИМК РАН);

к. и. н. Н. Ф. Соловьёва (ИИМК РАН); к. и. н. А. И. Торгоев (Государственный Эрмитаж); к. и. н. Е. А. Черлёнок (Институт истории СПбГУ)

Организационный комитет конференции: к. и. н. А. В. Поляков (ИИМК РАН, председатель);

к. и. н. В. А. Алёкшин (ИИМК РАН, зам. председателя); В. С. Бочкарёв (ИИМК РАН); ); к. и. н. М. Т. Кашуба (ИИМК РАН); д. и. н. Л. Б. Кирчо (ИИМК РАН);

А. И. Климушина (ИИМК РАН, отв. секретарь); к. и. н. В. П. Никоноров (ИИМК РАН); Ю. Ю. Пиотровский (Государственный Эрмитаж); В. Я. Стёганцева (ИИМК РАН); В. В. Терёхина

(ИИМК РАН, МАЭ РАН, отв. секретарь); к. и. н. Е. С. Ткач (ИИМК РАН); И. Ж. Тутаева (Государственный Эрмитаж); к. и. н. Е. А. Черлёнок (Институт истории СПбГУ)

Древности Восточной Европы, Центральной Азии и Южной Сибири в контексте связей и взаимодействий в евразийском культурном пространстве (новые данные и концепции): Материалы Международной конференции, 18-22 ноября 2019 г., Санкт-Петербург. Т. I. Древняя Центральная Азия в контексте евразийского культурного пространства (новые данные и концепции). К 90-летию со дня рождения патриарха евразийской археологии Вадима Михайловича Массона. - СПб.: ИИМК РАН, Невская Типография, 2019. — 291 с.

ISBN 978-5-907053-34-2

DOI 10.31600/978-5-907053-34-2 


\section{THE NEOLITHIC OF THE SOUTHERN CAUCASUS}

Tufan I. Akhundov

Institute of Archaeology and Ethnography of the Azerbaijan National Academy of Sciences,

Baku, Azerbaijan

Keywords: Neolithic, Mugahan, Karabakh, South Caucasus, Front Asia, Polutepe, ceramics, economy, tradition.

The problem of the initial entry of the Southern Caucasus into the epoch of Neolithic still has no single solution. Some researchers see its relation to the South-Caucasian Mesolithic; the others consider that the productive economy in the Southern Caucasus was introduced there in a ready form by the migrants from the Front Asia. In the Southern Caucasus it appeared in the developed form.

Presently, we distinguish the following four areas of the Neolithic tradition in the Southern Caucasus: Colchis or the Black Sea coast, Shomutapa or the Central Southern Caucasus, Karabakh and Mughan.

The Mughan Neolitic is represented by ashy hills $7 \mathrm{~m}$ in height, 0,25-6,0 ha, and thickness of the Neolithic layer is $6 \mathrm{~m}$. Ceramic material of this tradition at times superior the other Neolithic traditions of the Southern Caucasus. Ceramic material of this tradition is characterized by a diversity of forms and technology of molding, the inclusion of vegetable admixture, engobing, large percentage of painted samples and presence of massive loop-like handles. The economic basis consisted of agriculture, cattlebreeding, hunting and fishing. The Mughan Neolitic is dated to the late $5^{\text {th }}-$ the turn of the $5^{\text {th }}$ and $4^{\text {th }}$ millennia BC.

\section{ФОРМИРОВАНИЕ НОВОГО СОЦИАЛЬНО-КУЛЬТУРНОГО ПРОСТРАНСТВА - РАННЕЗЕМЛЕДЕЛЬЧЕСКОЙ КУЛЬТУРЫ КАРАБАХА НА ЮЖНОМ КАВКАЗЕ В ЭПОХУ НЕОЛИТА}

\section{Х. И. Алмамедов}

Институт археологии и этнографии НАН Азербайджана, Баку, Азербайджан

DOI: 10.31600/978-5-907053-34-2-100-102

Ключевые слова: Южный Кавказ, Карабахской неолит, поселение Исмаилбейтепе, Карабахская неолитическая-энеолитическая экспедиция, кремация, трепанация.

Эпоха неолита, характеризующаяся возникновением ранних земледельческих культур, явилась поворотным этапом в истории человечества. Благоприятные природно-географические условия Карабахской равнины соответствовали потребностям земледельческоскотоводческих племен, обусловили их расселение на этой территории с VI тыс. до н. э. и оказали сильное влияние на их духовную жизнь.

Работы по изучению ранних поселений земледельческо-скотоводческих племен Карабаха начала Азербайджанская археологическая (Оренкалинская) экспедиция, организованная ЛОИА АН СССР и Институтом истории АН Азербайджанской ССР в 1953 г.

В 1960-1990-е гг. раскопки поселений ранних земледельческо-скотоводческих племен Карабаха проводила Миль-Карабахская экспедиция под руководством известного азербайджанского ученого, д-ра ист. наук Идеала Гамид оглу Нариманова. В результате археологических разведок на Миль-Карабахской равнине были зафиксированы десятки новых поселений, а на памятниках Иланлытепе в 1967-1968 гг. и Чалагантепе в 1980-1985 гг. были проведены широкомасштабные стационарные раскопки. 
В течение 2010-2017 гг. Карабахская неолитическая-энеолитическая экспедиция осуществила широкомасштабные разведки, в результате которых были зафиксированы более 300 археологических памятников, причем 156 из них являются поселениями ранних земледельческо-скотоводческих племен.

По топографии распространения памятников Карабахскую равнину в период неолита можно сравнивать с Анатолией, Ираном и междуречьем Тигра и Евфрата. Выявленные на Карабахской равнине неолитические поселения количественно превосходят памятники, известные для этой эпохи на Южном Кавказе, как минимум в два раза. Плотность распространения поселений и выводы, сделанные в процессе их изучения, позволяют выдвинуть идею о том, что территория Карабаха являлась одним из основных очагов культуры кавказского неолита в VI тыс. до н. э. Результаты упомянутых полевых изысканий открывают возможности для изучения моделей расселения оседлого населения на Карабахской равнине в рассматриваемую эпоху.

Для изучения вопросов зарождения, развития и распространения неолитической культуры на Карабахской равнине на поселении Исмаилбейтепе с 2012 г. проводятся широкомасштабные археологические раскопки, в результате которых обнаружены и изучены остатки 15 строений округлой и прямоугольной форм, относящихся к четырем строительным периодам. Зафиксировано более 4000 фрагментов керамики, каменные и костяные орудия труда.

Уникальная архитектура и артефакты Исмаилбейтепе свидетельствуют об инновациях в неолите Кавказа. Для архитектуры памятника наряду с местными традициями характерны некоторые особенности домостроительства Анатолии и Ирана периода позднего неолита, включая оформление границ поселения каналами и высокими стенами. Высота выполнявшей оборонительные и охранные функции стены Исмаилбейтепе достигала 4-4,5 м, а ширина составляла около метра. Она делила поселение на внутреннюю и наружную части, причем внутри находились округлые дома, а снаружи - прямоугольные. В полы домов была вкопана глиняная посуда.

Наряду с обрядом ингумации в погребальном обряде представлена и кремация. Отмечены случаи трепанации и искусственной деформации человеческих черепов. Найдены бусы из малахита, изготовленные холодной ковкой. В качестве сырья для краски использовали охру и магнетит.

Для определения хронологии памятника из различных уровней его культурного слоя были взяты образцы ${ }^{14} \mathrm{C}$, которые анализировались в лабораториях Израиля (D-REAMS Radiocarbon Laboratory Weizmann Institute of Science) и Германии (Klaus-TschiraArchäometrie-Zentrum Am Curt-Engelhorn-Zentrum Archäometrie gGmbH). Полученные даты свидетельствуют о существовании поселения во второй четверти VI тыс. до н. э.

Итоги археологических исследований памятников земледельческо-скотоводческой культуры, расположенных на Карабахской равнине, позволяют говорить, что этот регион являлся центром формирования местной неолитической культуры в VI тыс. до н. э. В указанный период прогрессивные традиции, передаваемые с юга на север или в обратном направлении, обусловили формирование на территории Карабаха нового для неолита Южного Кавказа социально-культурного пространства - раннеземледельческой культуры Карабаха. Особенности архитектуры и технико-технологические различия, проявляющиеся в изготовлении керамики, позволяют отличать культуру неолита Карабаха от других неолитических культур Кавказа. 


\title{
THE FORMATION OF A NEW SOCIO-CULTURAL AREA - \\ THE EARLY AGRICULTURAL CULTURE OF KARABAKH \\ OF THE NEOLITHIC AGE IN THE SOUTHERN CAUCASUS
}

Khagani I. Almammadov

Institute of Archaeology and Ethnography of the Azerbaijan National Academy of Sciences, Baku, Azerbaijan

Keywords: South Caucasus, Neolithic of Karabakh, Karabakh Neolithic-Eneolithic Expedition, Neolithic settlement Ismailbeytepe, cremation, trepanation.

During 2010-2017, the Karabakh Neolithic-Eneolithic Expedition in the Karabakh Plain carried out archeological excavations on an area of about $3600 \mathrm{~km}^{2}$. As a result more than 300 archeological sites were registered. In particular, we would like to note that 156 of these registered sites are settlements of early farmer-breeder tribes.

Since 2012, the large-scale archaeological excavations were carried out in a Neolithic-period site of Ismayilbaytepe to study the issues of the formation, development, and spread of the Neolithic culture in the Karabakh Plain. Ismailbaytape is a novelty for the Caucasian Neolithic because of its unique architectural structure and discovered artifacts. In addition to local traditions in the South Caucasus, this Neolithic settlement demonstrates some architectural features of Late Neolithic Anatolia and Iran.

\section{АЛИКЕМЕКТЕПЕ - ПАМЯТНИК ЮЖНОКАВКАЗСКОЙ ГРУППЫ РАННЕЗЕМЛЕДЕЛЬЧЕСКОЙ КУЛЬТУРЫ АЗЕРБАЙДЖАНА}

\author{
Р. Б. Аразова \\ Университет Хазар, Баку, Азербайджан \\ DOI: $10.31600 / 978-5-907053-34-2-102-105$
}

Ключевые слова: Азербайджан, древнее земледелие, Аликемектепе, серпы разных типов, домашнее производство, обработка дерева, кости, кожи, керамики.

Аликемектепе - один из уникальных памятников высокоразвитой оседло-земледельческой культуры района Мугани в Азербайджане. В результате археологических раскопок здесь были обнаружены сырцовые постройки, гончарные печи, богатый керамический комплекс, орудия из кремня, обсидиана, кости и др.

Широкое внедрение трасологического метода в практику археологических исследований дало возможность комплексного изучения орудий труда. Результаты функциональной классификации показали, что в производственном инвентаре основное место принадлежит земледельческим орудиям, среди которых представлены кремневые, реже обсидиановые вкладыши серпов (рис. 1, 2-5) со следами интенсивной сработанности лезвий и остатками битума на обушковой части. Реконструкция формы серпов показала, что на Аликемектепе встречаются крупнозубчатые серпы, но предпочтение отдавалось составным серпам с прямым лезвием и однопластинчатым (рис. 1, 6, 7). Совершенствуя технику изготовления, способы размещения и крепления вкладышей в обойме рукоятей, древние земледельцы поселения тем самым повышали производительность жатвенных орудий. Эксперименты подтвердили, что самыми эффективными являются составные серпы с прямым лезвием и однопластинчатые: они только в 1,7 раза уступают по производительности современным железным орудиям. Серпы с прямым лезвием и однопластинчатые известны на соседних территориях Кавказа и на синхронных памятниках Ближнего Востока.

Среди других земледельческих орудий выделены роговые мотыги (рис. 1, 1, 9), землекопалки, лопаты. Зернотерки обычно имеют овальную форму, но встречаются и ладьевидные, которые позднее характерны для куро-араксской культуры. 